\title{
VINDIMA: UM ESTUDO DE CASO SOBRE O CAMPO DO DESIGN COMO TRADUTOR DA IDENTIDADE CULTURAL DE POPULAÇÕES NA CONCEPÇÃO DE ARTEFATOS INTERATIVOS
}

\author{
André Luiz Batista Abrahão \\ Universidade de Coimbra Portugal \\ andreabrahao@gmail.com \\ Alexandre Santos de Oliveira \\ Faculdade Fucapi \\ olialx@gmail.com
}

\begin{abstract}
Resumo: Este trabalho tem como objetivo apresentar o resultados referente ao processo de formulação do conceito de Vindima obtidos através da pesquisa sobre o comportamento de uso dos idosos de nacionalidade portuguesa com uma aplicação multitouch de caratér lúdico e reabilitivo. Tomando como base os conceitos de região, tradição e a ideia de que campo do design constitui-se numa atividade de tradução identitária, os resultados obtidos apontam para uma maior familiaridade e motivação deste público com o protótipo de jogo. Afinal, emular atividades do mundo real na interface pode constituir-se em uma efetiva estratégia na projetação de aplicativos.
\end{abstract}

Palavras-chave: identidade cultural, idosos, design, jogo.

\begin{abstract}
This work aims to present the results on the process of formulating the concept of Harvest obtained through research on usage behavior of elderly Portuguese nationals with a multitouch application playful and rehabilitative character. Based on the concepts of region, tradition and the idea that the field of design activity constitutes a translation of identity, the results obtained indicate a greater familiarity and motivation of the public with the game prototype. After all, to emulate real-world activities in the interface can form themselves into an effective strategy in the planning application.
\end{abstract}

Keywords: cultural identity, elderly, design, game. 


\section{INTRODUÇÃO}

Idosos, diferente da geração nascida no universo dos ícones e da internet, têm revelado grandes dificuldades em assimilar o significado da linguagem metafórica imposta pelos meios eletrônicos. Ações corriqueiras como a manipulação de menus para televisores ou operar caixas eletrônicos, tornam-se tarefas difíceis devido às características psicobiológicas e cognitivas que norteiam o envelhecimento humano.

No entanto,dentro deste contexto tecnológico, é relevante ressaltar a consolidação da interação por toque. Nesse caso, é pressuposto que a eliminação dos mecanismos tradicionais de input, como o mouse, teclado ou joysticks proporcionem uma interação mais direta, natural e intuitiva para todos os tipos de usuários.Porém, esta afirmação torna-se controversa quando lidamos com idosos.Pois, assim como podem ser eficazes na redução de carga cognitiva, podem ser inadequadas à tarefas que envolvem precisão, devido a ativação acidental por decorrência do Parkinson ou Artrite.

Essa dicotomia eleva a formulação de hipóteses sobre as potencialidades e limitações desta tecnologia pela população idosa, além de nortear a realização deste estudo.

Uma das estratégias para a maior aceitação do público seria a utilização de padrões de gestos e elementos de interface baseados em metáforas condizentes com a identidade cultural do utilizador idoso. Para isso é importante considerar hábitos, valores, crenças, rituais, práticas e costumes que fazem referência a uma herança cultural. A vindima, como tradicional festa portuguesa de coleta de uvas, serviu como base para o desenvolvimento de um protótipo de jogo cuja função foi incentivar e tornar o contexto de uso bem próximo da realidade do público idoso.

Desta forma, o presente artigo tende a apresentar o resultados referentes a utilização desta tradicional festa como base para o desenvolvimento de um protótipo de jogo de caráter lúdico e reabilitativo.Os resultados foram obtidos por meio da analise de ações e comportamentos de 12 idosos. A avaliação da emoção dos utilizadores foi baseada em um conjunto de 10 heurísticas propostas por Lera (2007), denominadas heurísticas emocionais. Estes registros foram realizados por meio da gravação de vídeos e aplicação de questionários de satisfação de tarefas.

\section{DESENVOLVIMENTO}

Pesquisadores defendem a fuga do estereotipo quando relacionamos o uso de meios informáticos e idosos, afinal, entende-se que este público não está mais recluso. Porém, observa-se que muitos produtos não atendem as especificidades deste público, principalmente no que diz respeito aos aspectos fisiológicos, cognitivos e culturais. A desconsideração destes podem ocasionar frustração ou sentimento de incapacidade. Uma das estratégias para o bom uso do sistema são as metáforas, estas podem ser uma forte aliada na redução da carga cognitiva visando promover a confiança e motivação para explorar um novo sistema.

O estudo da interação dos idosos de nacionalidade portuguesa com um protótipo de jogo baseado em atividades culturais quotidianas serviu como base para a apresentação dos resultados deste estudo. A partir disso, entende-se que antes de contextualizar a importância da tradição identitária na concepção de artefatos interativos é relevante abordar sobre questões relacionadas aos conceitos de Região e 
Tradição e em seguida contextualizar o Projeto Vindima.Os resultados alcançados e a aceitação do público concluindo com as oportunidades que a referida discussão propicia.

\subsection{Conceitos de Região e Tradição \\ Região}

Num momento em que o desenvolvimento de dispositivos interfaciais tendem a um atendimento cada vez maior das necessidades específicas dos usuários, estudos que abordam as influências territoriais e socioculturais, tornam-se cada vez mais necessários. É considerando este cenário que, neste trabalho, apresentamos as ideias de região e tradição como base para pensar o conceito da Vindima utilizado no desenvolvimento de uma interface multitouch direcionada a usuários seniores.

É certo que o uso do termo região, tanto para designar uma área onde se localiza uma atividade produtiva, uma área com características geográficas específicas, ou ainda a região enquanto unidade política e administrativa, tomam a delimitação espacial como o marco de referência, sem que a utilização desta terminologia qualifique, na totalidade, a multiplicidade e diversidade da realidade a que se refere (Breitbach,1988 p. 18). Sob esta ótica, a região é vista a partir das relações dialéticas entre o espaço e os processos histórico-culturais que modelam os grupos sociais (Correa, 1995 p. 21; Santos, 2001 p. 80-81).

No entanto, estas leituras sobre o fenômeno região podem ser compreendidas como tentativas para explicar o processo que Milton Santos (2006 p. 165) denomina de "universalidade atual do fenômeno da região". Para ele, no decorrer da história, as civilizações foram configurando-se por meio de processos orgânicos em que a territorialidade, a identidade, a exclusividade e os limites constituíam-se nas características definidoras da solidariedade de um entorno e de uma região.

Contudo, a aceleração com que ocorrem as transformações mundiais e, em especial aquelas ocorridas nos pós-guerras, colocaram em cheque as temporalidades que regiam as configurações regionais. Para Santos (2008 p. 167), tais transformações, que têm como principal vetor o fluxo de capitais, geram processos de mensuração e homogeneização das realidades locais/regionais sob uma perspectiva acrítica influenciando, tanto as organizações espaço-temporais existentes como aquelas que vão se estruturar em sequência.

Para Milton Santos, uma região precisa ser vista tomando em conta a sua inserção nos diversos cenários, além de ter em consideração o preexistente e o novo, como estratégia necessária para captar o elenco de causas e consequências do fenômeno (Milton Santos, 1988 p. 17). Isto porque os espaços regionais, conforme observa Theotonio Santos (1998 p.78), mantêm uma irredutibilidade impossível de ser substituída por outros espaços, qual sejam, os espaços nacional e global. Para ele, esses espaços, nacionais e globais, podem interferir sobre a conformação dos espaços regionais, orientando-os, mas nunca os substituindo.

\section{Tradição}

Fenômeno análogo pode ser observado na ideia de tradição. Falar em tradição remete ao passado e ao presente e porque não dizer ao futuro. Trata-se de um termo que convida a pensar em hábitos, valores, crenças, rituais, práticas e costumes que fazem referência a uma herança cultural e que, seguindo a etimologia da palavra, 
foram entregues, transmitidos e transferidos sem que se tivesse uma prova de autenticidade ou de veracidade, além do prestígio e da garantia de pertença a tempos imemoriais (Abbagnano, 2000 p. 967).

A circularidade que as ideias de transmissão e transferência evocam, tanto permitem pensar a tradição como um fenômeno que conjuga passado e presente como indicam as estratégias que a sociedade e a cultura utilizam para a sua constante atualização. Alguns desses procedimentos podem ser lidos em conceituações da tradição que põe em relevo dualidades tais como: civilizado e primitivo, antigo e novidade, passado e presente, tradição e modernidade. Talvez no aprofundamento destas dualidades resida, tanto a desconfiança como a celebração que foi sendo produzida em torno do termo tradição.

Um dos primeiros embates que põe em questão a tradição ocorre no iluminismo. Advogando a necessidade de estabelecer princípios racionais de compreensão e organização política e social, este movimento cultural insurgiu contra as intolerâncias e abusos da igreja e do Estado absolutista, propondo a extensão dos princípios e benefícios do conhecimento científico a todos os setores da vida social. Neste afã e impulsionados pela ideia de progresso, os partidários das luzes acreditavam que a superação do legado de tradição e superstição que havia governado a cultura ocidental, até aquele momento, conduziria a sociedade a um estado de esclarecimento e de constante aperfeiçoamento, ao tempo que passa a ser associada à ideia de erro a ser corrigido pela imposição da razão moderna como medida e como ethos universalista (Silva, 2007 p. 13).

Esse ethos não demora a ser questionado, animado pelo idealismo romântico de crítica ao instrumentalismo iluminista. O retorno à cultura popular, a saudade das origens, a ênfase no naturalismo e na subjetividade do eu, ao mesmo tempo em que criam o cenário propício à aventura modernista, no início do século $\mathrm{XX}$, desencadeiam novamente a pergunta sobre a identidade da nação, em que a (re)descoberta e/ou criação de tradições apresenta-se como uma resposta possível.

No entanto, esta ideia de tradição inclina-se para a redução do antigo e do passado e, por conseguinte, coloca a tradição, em um estado de inércia, que trava a possibilidade de que o passado possa ser visto a partir do seu potencial de força e de renovação (Santos, 2008 p. 53-54), questão essa que, tem causado certo mal-estar em torno da questão da tradição. Ao invés do passado e, por conseguinte de uma tradição, vistos como objetos neutralizados e incapazes de proceder à renovação criativa, reivindica-se um olhar para o passado e para a tradição, que ele muitas vezes abriga, reanimado, inventivo, dinâmico e encarnado numa outra lógica temporal.

\subsection{0 campo do design: tradução identitária e concepção de artefatos}

Ocupado com o processo de criação e transformação das culturas material e imaterial, o campo do design está atento à conjugação de aspectos estéticos, formais, funcionais, éticos, de uso, comunicacionais, dentre outros que objetivam a concepção de produtos e processos a serem utilizados pelos humanos no desempenho das mais diversas atividades cotidianas. Por sua preocupação com o uso, com o utilizador e com o contexto do uso, o trabalho do design acaba por absorver, utilizar-se, apreender e traduzir aspectos da realidade circundante desencadeando ações de identificação entre produto e utilizador, ao criar e recriar a própria cultura material (Oliveira, 2013 p. 133). 
Assim, uma leitura sobre o campo do design como locus de tradução deve ter em conta, pelo menos, três questões básicas, a saber: (1) a ênfase na ideia de tradução como locus de apropriação e transformação criativa da realidade, (2) os desdobramentos desta apropriação criativa que podem vir a ser materializados nos mais diversos suportes e servir a diferentes fins, no âmbito da sociedade, (3) ter em conta que esta produção criativa participa do circuito de produção e reprodução de identidades por meio da tradução identitária (Oliveira, 2013 p. 133).

Tomando essas questões como basilares para pensar o Projeto Vindima, é possível entender que a tradução não se apresenta como uma ação casual e livre de intencionalidade. Ela é entendida como um fazer que responde a determinados objetivos no contexto das relações de uso, de contato, de reprodução e de disseminação. Por ser a tradução possuidora de uma intencionalidade, é possível que, na esfera da racionalidade cognitivo instrumental da ciência e da técnica, criem-se estratégias e estruturas que permitam a sua reprodução a partir de determinados padrões de tradução, consagrados por uma dada forma de interpretação da realidade, assente nas premissas de completude e de totalidade.

Desta forma, ao considerar os aspectos da região e da tradição enquanto elementos conceituais de aproximação entre os usuários/interface constitui-se num trabalho de tradução levado a efeito pelo campo do design, baseado em pelos menos duas proposições necessárias à tradução identitária, tal como defendidas por Oliveira (2013, p. 135-139), a saber:

(1) As ações levadas a termo pela tradução identitária são localizadas e temporais. Esta proposição pode ser lida por pelo menos dois aspectos: o primeiro entende que a tradução identitária possui uma história, é fruto de determinada conjuntura sociopolítica e fala de um determinado grupo de sujeitos portanto, discursa a partir de um lugar, de um território, de uma região e move-se através da prática dos sujeitos envolvidos no percurso da tradução

(2) A tradução identitária ocupa-se tanto do centro como das margens e das periferias. Quando visa ainda resgatar elementos da tradição que foram apropriados e/ou parcialmente suprimidos pelo afã de totalidade da modernidade, mas que não foram de todo esgotados, sacralizados (explorados) pelo discurso hegemônico. Ela se ocupa ainda das representações incompletas, marginalizadas e relegadas à condição de inexistentes, tanto pelas dificuldades de enquadramento como pela abrangência limitada dos cânones vigentes.

\subsection{Contextualização do Projecto Vindima}

O projeto Víndima surgiu a partir desta preocupação com a tênue linha entre a infoexclusão e a boa possibilidade de interação destes usuários com os dispositivos multitouch. Metodologicamente, o estudo foi divido em duas partes: A primeira consistiu na proposição de seis heurísticas de usabilidade baseadas na interação multitouch e a segunda compreendeu a comprovação ou refutação destas por meio de um protótipo de jogo interativo multitouch, baseado em uma atividade quotidiana e familiar à realidade do usuário idoso a saber: as ideias de região e tradição.

Todas estas seis heurísticas propostas tendem a promover equitativamente os exercícios cognitivos e motores para o público idoso (Abrahão,2013).São elas: Feedback Bimodal, Dimensionamento e espaçamentos adequados, Consistência 
gráfica e de interação, Quantidade limitada de affordances/pontos de interação, Interfaces condizentes com a acuidade visual e Metáforas Apropriadas.

Particularmente,a última heurística denominada de metáforas apropriadas é a mais relevante para a abordagem deste artigo. As metáforas são essenciais para oferecer atalhos cognitivos para os utilizadores, através de modelos pré-existentes na memória quando estes aprendem a encarar novos sistemas. O uso deste conceito visa minimizar o esforço cognitivo dos idosos durante a utilização de qualquer sistema, compensando, assim, algumas limitações (Yousef, 2001). Portanto, é primordial o desenvolvimento de padrões de gestos e elementos de interface baseados em metáforas condizentes.

Uma das intenções para o desenvolvimento do protótipo do jogo é que seja um artefato que remeta a aspectos culturais, ao quotidiano do idoso, de forma que ele não sinta-se hostilizado durante a interação. Portanto, uma das primeiras etapas para o desenvolvimento do protótipo foi buscar dentro da cultura portuguesa algum movimento ou festa popular em que a essência fosse a confraternização entre diferentes gerações de uma família. Nesse caso, optou-se pela festa da Víndima.

A Vindima, num sentido mais lato, consiste na colheita dos cachos de uvas destinados à produção de vinho, quando estas atingem o grau indicado de amadurecimento. Normalmente as datas da vindima são caracterizadas pelo movimento sazonal de dezenas de trabalhadores oriundos de terras vizinhas que contribuem para a colheita.Muitas vezes são famílias completas que se deslocam numa tradição que atravessa gerações: as mulheres, auxiliadas pelas crianças, cortam os cachos, que são colocados em cestas de vime, cabe então aos homens transportar estes cestos para os lagares. Na Região do Douro, a mais antiga região demarcada de vinho do mundo é comum a organização de festas, numa tradição histórica que perdura por gerações entre famílias.

Momentos familiares como estas possuem um significado especial para o idoso, Afinal, a função comunitária da festa para o grupo familiar e para cada um dos seus membros transporta o tema para o âmbito da vivência e do crescimento pessoal, familiar, moral e social, constituindo um desafio à ação educativa, social e terapêutica (Pinto,2010). As etapas de coleta, transporte e esmagamento de bagos de uva foram relevantes para desenvolvimento da identidade visual, interação e mecânica do jogo.

Com o conceito definido, todas as partes relacionadas ao design foram projetadas; sobretudo uso das cores da aplicação remetendo às uvas touriga bem tradicionais na Região do Douro. Os ícones relacionados às três tarefas propostas pelo protótipo e principalmente a consideração dos gestos de "tap" para seleção dos targets e esmagamento dos bagos, o "flick" para o corte dos cachos e o "drag" para simular um caminho com os dados entre os targets (Figura 3). Essa associação é necessária, pois, a metáfora é proposta quando o gestual seja correspondente ao contexto real, tornando a interação mais natural e intuitiva possível.

A primeira fase do jogo denominada de coleta é caracterizada pelo exercício da acuidade visual e motora. Esta parte do protótipo tem a função de medir a efetividade de duas heurísticas: dimensionamentos e espaçamentos adequados e interfaces condizentes com a acuidade visual. Idosos possuem dificuldade em distinguir tons cromáticos, desta forma, a primeira tarefa é identificar e "apontar" ao longo da extensa plantação verde, pistas visuais (affordances) que indicam a exata localização de pontos para vindimar (Figura 1). 

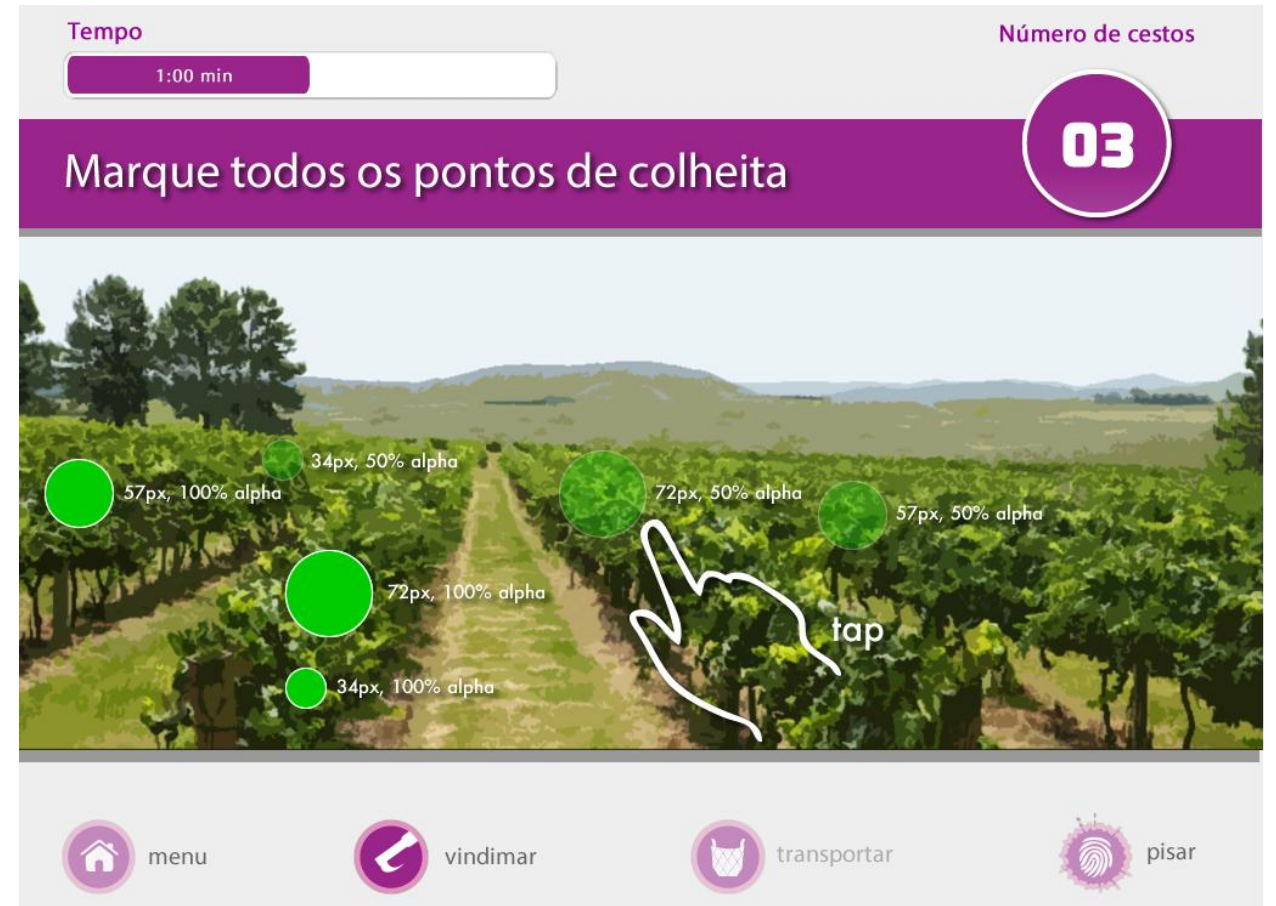

Figura 1 - Atividade de coleta de bagos de uva. Elaborado pelo autor conforme pesquisa realizada

Estes pontos de indicação podem mudar de posicionamento, cor e tamanho. 0 dimensionamento do affordance pode evidenciar o target adequado para o utilizador idoso. Ao dar o "tap" em cada um dos affordances há a abertura de uma tela popup que fazem uma representação de um arbusto composto por cachos de uvas inseridos em um emaranhado de folhas (figura 2). A heurística dimensionamentos e espaçamentos adequados será exercitada por meio da tarefa se separação dos cachos com os arbustos através do gesto "flick". A distância do "cabo" e o arbusto compõem o exercício para a calibração da heurística.

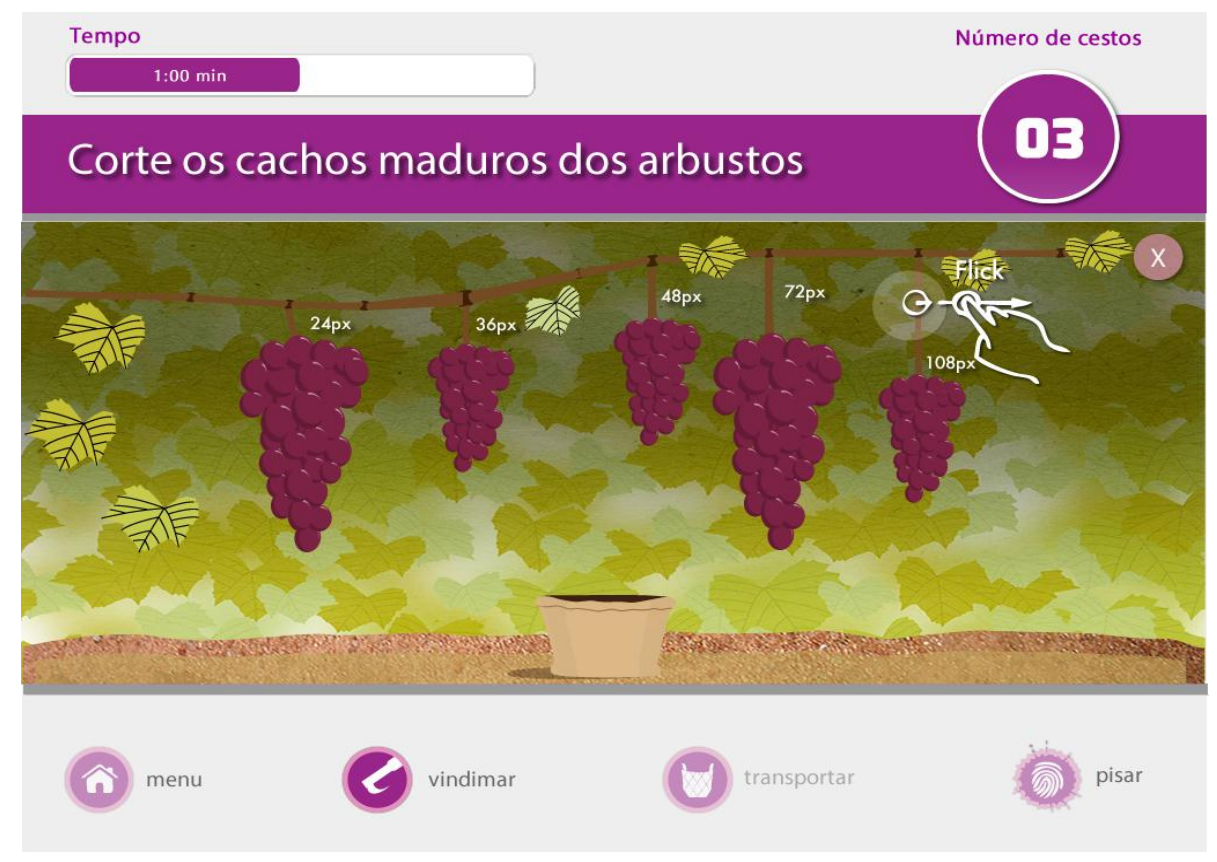


Figura 2 - Atividade corte de bagos maduros .Elaborado pelo autor conforme pesquisa realizada

A segunda fase denominada "transporte" tem como objetivo estimular a condução dos cestos de uva até os caminhões, o desafio consiste em levar os respectivos cestos, devidamente identificados por cores, aos respectivos caminhões com as mesmas cores. O jogador não pode tocar as vinhas, caso contrario, os cestos são perdidos. Para esta atividade do jogo estará sendo exercitada a acuidade motora. Esta atividade tenciona calibrar a heurística Consistência Gráfica e de Interação. Por definição, utilizadores idosos preferem padrões; a quebra da curva de aprendizado pode ocasionar erros e consequentemente o abandono do sistema. Desta forma, pretende-se verificar qual o comportamento de interação por touch do utilizador idoso em relação à alternância de posicionamento e aspecto cromático dos elementos gráficos do protótipo ao longo da tela (Figura 3).

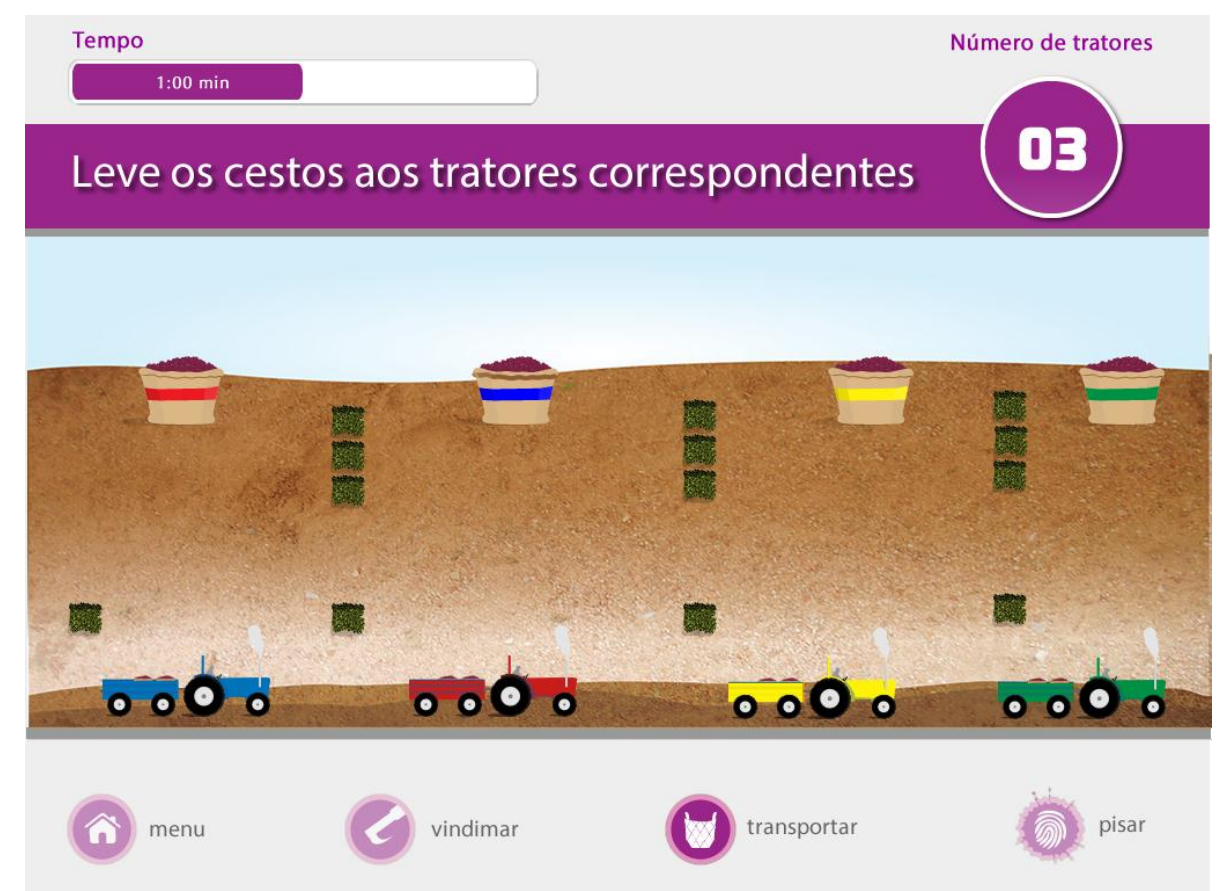

Figura 3 - Atividade de transporte de cestos de uva. Elaborado pelo autor conforme pesquisa realizada

A terceira atividade consiste em "pisar" em ordem sequencial numérica em cada uma dos bagos das uvas que aparecem na tela. Os bagos são mostradas num curto período de 05 segundos de modo que o jogador memorize a sequencia em que elas aparecem. Em uma ordem crescente de dificuldade, estes vão aparecendo em maior numero (Figura 4). 


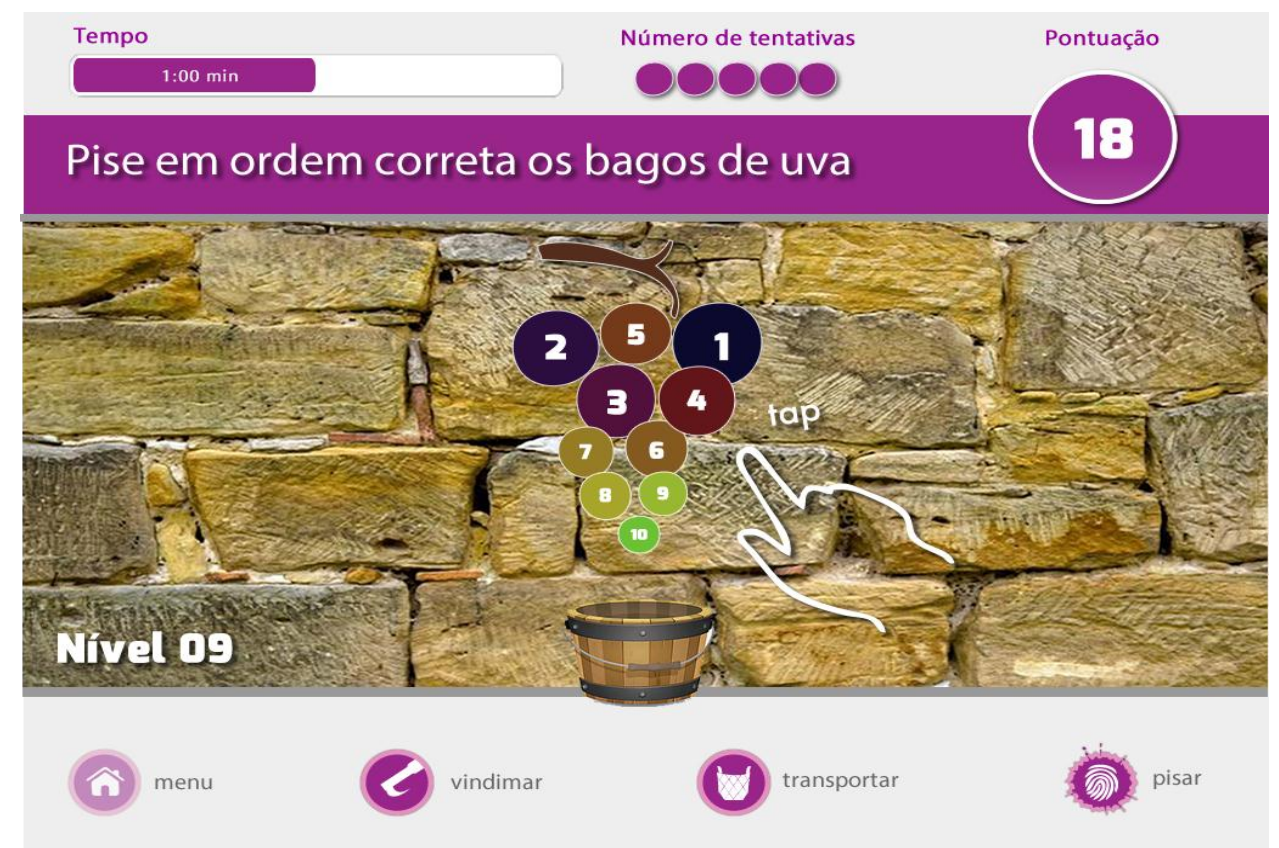

Figura 4 - Atividade esmagamento de bagos de uva.Elaborado pelo autor conforme pesquisa realizada

Para esta atividade serão exercitados o senso cognitivo, motor, auditivo e visual. Como um dos principais problemas enfrentados pelo público idoso é a dificuldade para recuperar informações de curta duração, algumas estratégias podem ser adotadas para atenuar esta problemática, como por exemplo, a consistência de informações, repetições de padrões e assistência sonora em complemento à informação visual.

\subsection{Resultados e aceitação do público}

Os resultados apresentados neste artigo relacionam-se com a compreensão dos elementos de jogo por parte do público idoso. Neste sentido, é importante compreender se houve a assimilação da analogia feita sobre a víndima por meio do artefato interativo e em que medida aspectos regionais e da tradição contribuíram para o alcance deste objetivo. Portanto, apesar de terem sido realizados testes de natureza quantitativa para mensurar a efetividade de heurísticas relacionadas à dimensionamento, espaçamento entre targets e naturezas de feedback (visão e audição), o mais relevante é apresentar o resultado dos usuários diante da heurística através de metáforas apropriadas.

Como estão sendo avaliadas questões relacionadas às emoções humanas diante da interação com o artefato interativo, o método Thinking-Aloud foi o mais adequado como estratégia para obtenção de dados qualitativos. Nestas sessões os participantes executam um número de tarefas com o sistema enquanto verbalizam suas ações e pensamentos, o método é relativamente simples de aplicar e bastante rico no que diz respeito à obtenção de informações de como, quando e porque dos problemas de utilização do sistema. Outra ação importante foi a avaliação comportamental dos utilizadores a partir de um conjunto de 10 heurísticas, emocionais (Lera, 2007). Estas heurísticas da emoção abrangem um conjunto de 10 itens para identificar as emoções de usuários durante a interação com um sistema, a saber: 1) testa franzida, 2) levantar as sobrancelhas, 3) olhar a distância, 4) sorrindo, 5) comprimindo os lábios, 6) mexendo a boca, 7) expressões vocais, 8) mão tocando a 
face, 9) indo para trás na cadeira e 10) inclinando para frente do tronco.

Esta analise foi realizada mediante a observação de vídeos de interação dos utilizadores com o protótipo; um instrumento de registro em papel norteou a ocorrência das emoções. Cada idoso foi filmado por duas câmeras comuns, uma localizada bem a frente e a outra na parte anterior a fim de capturar a interação dos dedos com o tablet. Ao finalizar as interações, os utilizadores responderam algumas questões sobre o protótipo, essas perguntas abrangeram o nível de dificuldade das tarefas propostas, além de questões relacionadas à compreensão da metáfora da vindima proposta pelo jogo.

Em todos os doze testes realizados houveram violações de heurísticas, nenhum idoso demonstrou-se impassivo diante das atividades, é importante ressaltar que antes dos testes todos permaneciam calados e receosos em cometer erros, grande parte tentava explicar o porque da falta de interesse em relação aos meios informatizados, como justificativa aos possíveis erros que achavam que viriam a cometer.

A atividadede de coleta foi a que teve maior índice de heurísticas violadas (91), seguidas da atividade de esmagamento de bagos (73) e a atividade de transporte com 63 violações. As quatro heurísticas mais recorrentes foram: a expressão vocal, com 72 incidências, a Inclinação do tronco para frente com 44 vezes e o sorriso com 27 aparecimentos. Observou-se que a dúvida de como proceder foi recorrente logo na primeira atividade, grande parte não atentou para as instruções e preferiu perguntar ao pesquisador ou a parentes que acompanhavam a avaliação.

Outras violações como a compressão dos lábios, o movimento da boca e mão tocando o rosto revelam a ansiedade e frustração com o erro. A inclinação do tronco para a frente mostra o engajamento em a cumprir a tarefa com precisão, observou-se que $90 \%$ dos avaliados optou por deixar o tablet apoiado sobre a mesa por receio em deixá-lo cair. O sorriso mostra a sensação de superação durante a realização das atividades e segurança em criticar e propor melhorias à aplicação, algumas delas citadas a seguir:- "Poderias incluir música pra vindima ficar mais animada" ou "Poderias colocar carros de bois em vez de camiões, antigamente o transporte era feito assim". Os questionários pós teste revelaram algumas críticas negativas para a tarefa de coletar/vindimar; Muitos dos utilizadores não perceberam o significado da identificação dos targets verdes. Apenas dois citaram que esta tarefa está relacionada à identificação dos arbustos com mais bagos para coletar. No entanto, a subtarefa de cortar os bagos teve uma boa receptividade, apesar de alguns sentirem falta da ferramenta de corte tradicional para realizar a ação. A atividade de transportar, talvez pela simplicidade, obteve críticas favoráveis de alguns usuários. Quase todos relacionaram as vinhas espaçadas da primeira atividade e a utlização de caminhões para fazer o transporte. A nomenclatura de "pisar" com os dedos foi criticada, afinal a tradicional é realizada com os pés. As ambientações dos lagares, os bagos de uva em tamanhos diferenciados conseguiram sensibilizar três utilizadores que identificaram estados diferentes de maturação.

\section{CONCLUSÃO}

Com a aplicação finalizada, um dos grandes desafios foi identificar um método adequado para "medir" a satisfação dos utilizadores em relação às metáforas do protótipo, afinal, a subjetividade é mais complicada de ser avaliada. A Metodologia 
denominada de As Dez Heurísticas da Emoção desenvolvidas por Lera (2007) foi a balisadora para a realização dos testes com o aplicativo. A partir dela foi permitido identificar o estado emocional dos usuários durante a interação pela observação de comportamentos.

No entanto, esse processo de avaliação não é simples, Lera (2007) defende que não é fácil avaliar as emoções humanas; Profissionais da usabilidade durante um bom tempo neglienciaram as emoções dos usuários ao basear seus testes na avaliação da satisfação do usuário, baseando-se no número de erros, tempo e outras medidas objetivas.

Em relação aos testes, grande parte dos usuários não dispunham de condições para locomover-se para a realização dos testes, desta forma, optou-se pelos testes controlados realizados em campo, portanto, houve a possibilidade de colocar 0 utilizador mais próximo ao contexto real de uso, evitando inibi-lo. Entende-se que o receio inicial foi aceitável, pois, a maioria nunca utilizou um terminal informatizado, sobretudo algo relacionado ao multitouch. No entanto, quase $90 \%$ dos avaliados sentiram-se mais à vontade quando souberam que a atividade de jogo estava relacionada à Víndima, pois, em algum momento de vida já participaram da colheita ou tinham conhecimento de como funcionava a atividade. As sugestões para a melhoria do aplicativo mostram a quebra do paradigma do usuário idoso passível à tudo o que Ihe é apresentado.

Portanto, esse processo de preocupação com o usuário e o contexto em que está inserido, sobretudo, na tradução dos aspectos de sua realidade, desencadeia ações de identificação entre produto e utilizador, ao criar e recriar a própria cultura material (Oliveira, 2013 p. 133).Desta forma, entende-se que os conceitos de Região, sobretudo, no que se refere à abordagem sobre as as influências territoriais e socioculturais, e a Tradição intrinsicamente relacionada aos hábitos, valores, crenças, rituais, práticas e costumes tornam-se cada vez mais necessários dentro do contexto do design.

Globalmente, espera-se que pesquisas desta natureza contribuam para estudos futuros sobre heurísticas com um foco sócio cultural, baseadas na mensuração das emoções dos usuários.Visto que, grande parte dos testes realizados medem a apenas a usabilidade dos sistemas computacionais não considerando os aspectos subjetivos da natureza humana. Norman (2004) acredita que um design com boa usabilidade e utilidade não necessariamente seja o mais agradável de usar, e que um design atrativo não seja o mais eficiente. Desse modo, deve-se haver um equilíbrio entre a usabilidade, funcionalidade e a experiência emocional.

$O$ resgate da memória de maneira lúdica por meio das interfaces basedas nos aspectos culturais oportunizariam trabalhos futuros de concepção de artefatos com estâncias mais complexas.

\section{REFERÊNCIAS}

ABBAGNANO, N. Dicionário de filosofia. 4a Ed. São Paulo: Martins Fontes, 2000.

ABRAHÃO, André Luiz et al. A study on the accessibility of touch and gesture interaction with senior users through a prototype game based on the activity of "vindima". In Proceedings do XII Simpósio Brasileiro de Jogos e Entretenimento Digital (SBGames 2013) ISSN: 2179-2259. Disponível na internet por http em: 
http://www.sbgames.org/sbgames2013/proceedings/comp/24-full-paper.pdf. Acesso em 20 abri 2014 . São Paulo, 2013.

CORRÊA, Roberto. Região e organização espacial. 5a ed. São Paulo : Ática, 1995.

LERA, E. and Domingo, M. G.Ten Emotion Heuristics: Guidelines for assessing the user's affective dimension easily and cost-effectively. In BCS-HCl '07 Proceedings of the 21st British $\mathrm{HCl}$ Group Annual Conference on People and Computers, 2007.

SANTOS, B. de S. (org). Globalização: fatalidade ou utopia? Porto, Ed. Afrontamento, 2001.

SANTOS, Boaventura de Souza. A gramática do tempo: para uma nova cultura política. 2a ed. São Paulo: Cortez, 2008.

SANTOS, Boaventura de Souza. Renovar la teoría crítica y reinventar la emancipación social: encuentros en Buenos Aires. Buenos Aires: Consejo Latinoamericano de Ciencias Sociales- CLACSO, 2006.

SANTOS, Milton. A Natureza do Espaço: Técnica e Tempo, Razão e Emoção. (4a. ed.). São Paulo: Editora da Universidade de São Paulo, 2006.

SANTOS, Milton. Metamorfoses do espaço habitado, fundamentos teórico e metodológico da geografia. São Paulo: Hucitec, 1988.

SANTOS, Theotonio. dos. A globalização reforça as particularidades. In_SANTOS, M.; SOUZA, M.; A. A. de.; SILVEIRA, M. L. (orgs) Território, globalização e fragmentação (4a ed.). São Paulo: HUCITEC/ANPUR, 1998.

SILVA, Sidney Reinaldo. A civilização contra a tradição no projeto iluminista de Condorcet. In Anais da 30 a Reunião Anual da Anped. GT - 17 - Filosofia da Educação. Caxambú, $\quad 2007 . \quad$ Disponível em http://www.anped.org.br/reunioes/30ra/trabalhos/GT17-3001--Int.pdf. Acesso em 22.12.2012.

LE GOFF, Jaques. História e Memória. Campinas, SP: Editora da UNICAMP, 2003.

NORMAN, D.A. Why We Love (or Hate) Everyday Things. Basic Books, 2004.

OLIVEIRA, Alexandre. Santos de. Identidade cultural e ensino do design no Amazonas. 187 f. Tese (doutorado) - Pontifícia Universidade Católica do Rio de Janeiro - PUC-Rio. Programa de Pós-graduação em Design. Disponível na internet por http em: http://www2.dbd.puc-rio.br/pergamum/tesesabertas/0912508 2013 cap 4.pdf.

Acesso em 23 mar 2014.

PINTO.Contributos da psicologia para o estudo de rotinas, tradições, celebrações e rituais familiares. Comunicação \& Cultura, n.ㅇ 10, 2010. Disponível em: http://comunicacaoecultura.com.pt/wpcontent/uploads/04.-H.R.Pinto M.T.Ribeiro.pdf Acesso em 08 ago 2013.

YOUSEF, M. K. Assessment of metaphor efficacy in user interfaces for the elderly: a tentative model for enhancing accessibility. Disponível na internet por http em: http://doi.acm.org/10.1145/564526.564557,2001.Acesso em 20 ago 2013. Portugal, 2011. 